\title{
Identification of Putative Molecular Markers Associated with Root Traits in Coffea canephora Pierre ex Froehner
}

\author{
Devaraja Achar, ${ }^{1}$ Mallikarjuana G. Awati, ${ }^{2}$ M. Udayakumar, ${ }^{1}$ and T. G. Prasad ${ }^{1}$ \\ ${ }^{1}$ Department of Crop Physiology, University of Agriculture Sciences, Gandhi Krishi Vignana Ken-dra, Bangalore, \\ Karnataka 560 065, India \\ ${ }^{2}$ Division of Plant Physiology, Central Coffee Research Institute, Balehonnur, Chikmagalur District, Karnataka 577 112, India
}

Correspondence should be addressed to Devaraja Achar; dachar@rediffmail.com

Received 25 June 2014; Accepted 11 January 2015

Academic Editor: Surjit Kaila S. Srai

Copyright (C) 2015 Devaraja Achar et al. This is an open access article distributed under the Creative Commons Attribution License, which permits unrestricted use, distribution, and reproduction in any medium, provided the original work is properly cited.

\begin{abstract}
Coffea canephora exhibit poor root system and are very sensitive to drought stress that affects growth and production. Deeper root system has been largely empirical as better avoidance to soil water limitation in drought condition. The present study aimed to identify molecular markers linked to high root types in Coffea canephora using molecular markers. Contrasting parents, L1 valley with low root and S.3334 with high root type, were crossed, and 134 F1 individuals were phenotyped for root and associated physiological traits (29 traits) and genotyped with 41 of the 320 RAPD and 9 of the 55 SSR polymorphic primers. Single marker analysis was deployed for detecting the association of markers linked to root associated traits by SAS software. There were 13 putative RAPD markers associated with root traits such as root length, secondary roots, root dry weight, and root to shoot ratio, in which root length associated marker OPS1 ${ }_{850}$ showed high phenotypic variance of $6.86 \%$. Two microsatellite markers linked to root length $\left(\mathrm{CPCM} 13_{400}\right)$ and root to shoot ratio $\left(\mathrm{CM} 211_{300}\right)$. Besides, 25 markers were associated with more than one trait and few of the markers were associated with positively related physiological traits and can be used in marker assisted trait selection.
\end{abstract}

\section{Introduction}

The world's primary source of caffeine is the coffee "bean," which is the seed of the coffee plant, from which coffee is brewed and therefore it is one of the most important commodities in the international agricultural trade, representing a significant source of income to several coffee growing countries. The genus Coffea belongs to Rubiaceae family which has 500 genera and over 6,000 species, in which Coffea arabica $(2 n=44)$ and Coffea canephora $(2 n=22)$ are the two commercially cultivated species. Currently the production of arabica and robusta coffee accounts for $65 \%$ and $35 \%$, respectively; however arabica coffee typically contains half the caffeine of the robusta variety $[1,2]$. The world coffee production in 2012/2013 was 155,140 (in 1,000 60 kilogram bags), but then in 2013/2014 and 2014/2015 there is a decline in coffee production and it is predicted to be decreased. This decreased coffee production is predominantly associated with variable climatic conditions, particularly limited water stress (drought), where water shortages are responsible for the greatest crop losses around the world [3, 4]. In several coffee growing countries drought is considered to be the major environmental stress affecting coffee production, in particular Coffea robusta. Because the robusta coffee is shallow rooted, it has largely been cultivated in water constraint, experiencing the stress at various crop phenology, which impacts crop growth and development above ground [5-7].

Indeed drought-adapted plants are often characterized by deep and vigorous root systems, since root associated traits play a crucial role in maintaining canopy hydraulic conductance with high carbon assimilation in drought $[8,9]$. Breeding coffee plants for root traits to enhance the productivity under water stress is very much required, but little progress has been achieved due to quantitative nature and poor knowledge of the genetic control of drought tolerance. Furthermore, the quantitative nature of root traits could be either constitutive or adaptive, but difficult to phenotype. Therefore, it is not surprising that a majority of genetic 
research has focused on aboveground traits while the "hidden half" of the plant is much less represented in recent research [10]. With the conventional breeding methods, introgression of complex/quantitative traits is unfeasible. Molecular marker technology and genomics serve as a tool for selecting such complex traits and allow breeders to track genetic loci controlling drought resistance traits, without measuring the phenotype, thus reducing the need for extensive field testing over space and time [11-13]. With the functional genomics it was shown that the increase in the amount of RBCS1 (Rubisco small subunit) protein could contribute to the antioxidative function of photorespiration in water-stressed Coffea canephora plants [14]. Furthermore it was also shown that drought acclimation in Coffee canephora clones probably involving the abscisic signalling pathway and nitric oxide are major molecular determinants that might explain the better efficiency in controlling stomata closure and transpiration displayed by drought-tolerant clones of C. canephora [15].

With an advent of Next Generation Sequencing (NGS) technologies, Coffea canephora is the first coffee species fully sequenced [16]. The developed crop-specific hub, the Coffee Genome Hub (CGH) (http://coffee-genome.org/), can be exploited to identify the genes/SNP markers conditioning for drought and root associated secondary traits by resequencing intra- and interspecific genetic resources of robust coffee species [17]. Therefore, it is very important to identify the genetic loci conditioning root associated traits for breeding better drought tolerance clones. With this background, our study aims at (1) developing a mapping population with contrasting parental lines for root traits and phenotyping, (2) genotyping the mapping population with RAPD and SSR markers, and (3) detecting the association of molecular markers with complex physiological and morphological traits.

\section{Materials and Methods}

2.1. Plant Materials. To identify the markers linked to root and associated physiological traits, F1 mapping population was developed by crossing low root type L1 valley as female parent with high root type S.3334 as male parent. After successful pollination, matured 300 coffee fruits were sown in nursery and after 48 days and 135 healthy seedlings were transplanted to carbonized rubber containers ( $35 \mathrm{~kg}$ capacity) for better establishment. This experiment was conducted at Central Coffee Research Institute, Chikmagalur District, Karnataka State, India. Institute is situated at $13^{\circ} 22^{\prime \prime}$ north Latitude and $75^{\circ} 28^{\prime \prime}$ east Longitude at an elevation of 824 to 884 meters above mean sea level.

2.2. Phenotypic Analysis. The moisture regime of $70 \%$ field capacity (FC) was imposed for 180 days after six months of coffee seedlings established in carbonized rubber containers. Gravimetric approach was followed to maintain 70\% FC, where potted plants were daily weighed to add water which was evapotranspired [18].

2.3. Observations Recorded during Treatment Period. During the treatment period (180 days), cumulative water added, evaporation, evapotranspiration were recorded. After the treatment period, root traits such as root length $(\mathrm{cm})$, number of secondary roots, root dry weight (g/plant), shoot dry weight (g/plant), and root to shoot ratio were recorded. Besides, morphological, gravimetric, and gas exchange parameters were also recoded [19].

2.4. Genomic DNA Extraction. Coffee leaves were frozen in liquid nitrogen and stored at $-80^{\circ} \mathrm{C}$. DNA was extracted from frozen leaves using cetyltrimethyl ammonium bromide (CTAB) method [20]. For the CTAB technique, $900 \mu \mathrm{L}$ of $\mathrm{CTAB}$ extraction buffer was added to lyophilized leaf tissue in $2 \mathrm{~mL}$ Eppendorf tubes and then lightly vortexed. The tubes were placed in hot water bath $\left(65^{\circ} \mathrm{C}\right)$ for $45 \mathrm{~min}$ and mixed with $400 \mu \mathrm{L}$ of chloroform : isoamylalcohol $(24: 1)$ and centrifuged for $15 \mathrm{~min}$. The aqueous layer was collected, and $800 \mu \mathrm{L}$ of isopropanol was added to precipitate the nucleic acids. Nucleic acid pellets were washed with $400 \mu \mathrm{L}$ of $70 \%$ ethanol, dried, and resuspended in $100 \mu \mathrm{L}$ of Tris-EDTA buffer (10 mM Tris with pH 7.5 and 0.5 mM EDTA).

2.5. Polymerase Chain Reaction (PCR). RAPD (Random Amplified Polymorphic DNA, Operon Technologies) primers were used to genotype mapping population. Polymerase chain reaction was carried out in $15 \mu \mathrm{L}$ reaction containing $1 \mathrm{x}$ buffer, $2 \mathrm{mM}$ dNTPs, $2.5 \mathrm{mM} \mathrm{MgCl}_{2}, 5 \mu \mathrm{M}$ primer, and $1 \mathrm{U}$ Taq DNA polymerase (NEB). Amplification was performed with the following thermal cycle profile: $94^{\circ} \mathrm{C} / 4$ min hot start denaturation, followed by 35 cycles of $94^{\circ} \mathrm{C}$ for $1 \mathrm{~min}$, primer annealing at $38^{\circ} \mathrm{C}$ for $1 \mathrm{~min}$, extension at $72^{\circ} \mathrm{C}$ for $2 \mathrm{~min}$, and a final extension at $72^{\circ} \mathrm{C}$ for $8 \mathrm{~min}$. The PCR was performed using Eppendorf thermocycler (Eppendorf, Hamburg, Germany). The PCR products were run on $1.5 \%$ agarose gel at 90 volts for $1 \mathrm{~h} 30 \mathrm{~min}$ and amplified fragments were documented using Hero Lab Gel Documentation system (Inkarp).

SSR (simple sequence repeats) primers for polymerase chain reaction were synthesized based on the information available in coffee genome database and also from in-house developed from S.3334 coffee accession.

PCR amplification was carried out with $15 \mu \mathrm{L}$ reaction mixture having $50 \mathrm{ng}$ DNA, 1x PCR buffer, $100 \mu \mathrm{M}$ dNTPs, $250 \mu \mathrm{M}$ primers, and 1 unit Taq polymerase enzyme (NEB). Amplification was performed with the following thermal cycle profile: $95^{\circ} \mathrm{C}$ for $5 \mathrm{~min}$, followed by 35 cycles of polymerization reaction, each consisting of denaturation at $94^{\circ} \mathrm{C}$ for $15 \mathrm{~s}$, annealing at $60^{\circ} \mathrm{C}$ for $45 \mathrm{~s}$, and an extension step at $72^{\circ} \mathrm{C}$ for $1 \mathrm{~min}$. A final extension step was run for $5 \mathrm{~min}$ at $72^{\circ} \mathrm{C}$. The PCR was performed using Eppendorf thermocycler (Eppendorf, Hamburg, Germany). The PCR products were run on $6 \%$ polyacrylamide denaturing gels. Amplified fragments were detected using a silver-staining procedure (Promega, Madison, WI, USA).

2.6. Study of Parental Polymorphism. The contrasting parents $(\mathrm{L} 1$ valley $\times$ S.3334) for root traits were screened with 320 RAPD (series from OPK1 to OPZ20) and 55 SSR markers. The polymorphic RAPD bands were visually scored for the presence (1) or absence (0) and in SSR analysis the segregating band from the female parent was scored as 3, male parent as 1 , 
TABLE 1: Genotypic variation of parental accessions S.3334 (high root type) and L1 valley (low root type).

\begin{tabular}{lccc}
\hline & & S.3334 & L1 valley \\
\hline 1 & Root length & 45 & 30 \\
2 & Secondary roots & 40 & 15 \\
3 & Root dry weight & 31.81 & 4.95 \\
4 & Root to shoot ratio & 0.41 & 0.36 \\
5 & Total dry matter & 106.77 & 15.49 \\
6 & Cumulative water transpired & 28.86 & 31.15 \\
7 & water use efficiency & 3.72 & 3.62 \\
8 & Net assimilation rate & 13.75 & 9.09 \\
9 & Mean transpiration rate & 3.72 & 2.23 \\
10 & Pn $/ g_{s}$ & 78.39 & 43.78 \\
11 & $\mathrm{Pn} / E$ & 2.99 & 1.84 \\
12 & $\mathrm{Ci} / \mathrm{g}_{\mathrm{s}}$ & 3863.5 & 3399.4 \\
\hline
\end{tabular}

and heterozygous bands were scored as 2 in all individuals of F1 mapping population. The binary data was used for further statistical analysis. Based on the segregation of RAPD markers in the mapping population, the putative genotypic interpretation of the parents for the marker locus was made and the Chi-square test was performed (http://www.physics.csbsju .edu/stats/chi-square_form.html).

2.7. Association of Identified Polymorphic Markers with Physiological Traits. Single point analysis [21, 22] for detecting the association of molecular markers with complex physiological and morphological traits was done using SAS software. To find the amount of variability explained by these markers, regression $\left(R^{2}\right)$ values were worked out by one-way analysis of variance (ANOVA), by general linear model (GLM) procedure. In this analysis, different traits were treated as dependent variable and the various molecular markers as independent variables. A total of 30 different physiological and morphological traits were used to associate with the 85 polymorphic molecular markers [23].

\section{Results}

3.1. Phenotyping Root Length, Secondary Roots, Root Dry Weight, and Physiological Traits. At the end of experiment period about 180 days water stress, pots were completely saturated with water and then, in next day, all plants were carefully detached with water force to avoid root loss. The data on root length, secondary roots, and root biomass data of parental lines (Table 1) and F1 mapping population were recorded (Table 2). There was significant genetic variability observed in root length, ranging from $41.5 \mathrm{~cm}$ to $83.0 \mathrm{~cm}$ with a mean of $57.08 \mathrm{~cm}$. Similar trend was followed in dry weight, ranging from $2.57 \mathrm{~g}$ to $34.69 \mathrm{~g}$ with a mean of $13.81 \mathrm{~g} / \mathrm{plant}$, and root to shoot ratio varies from 2.57 to 4.41 with mean ratio of 3.77. It was observed that F1s root traits were distributed between the values of the respective parental lines without much considerable transgressive segregation (Figure 1). The quantitative nature of these traits showed continuous variation, confirming the metric nature of the traits.
Morphological traits such as plant height, number of nodes and leaves, stem girth, internodal length, leaf area, shoot dry weight, and total dry matter were recorded. Nonetheless, all these traits showed significant and continuous variation (Table 2). Besides, genetic variability in the mapping population in net photosynthesis $(\mathrm{Pn})$, stomatal conductance $\left(\mathrm{g}_{\mathrm{s}}\right)$, transpiration rate $(E)$, intrinsic WUE $\left(\mathrm{Pn} / \mathrm{g}_{\mathrm{s}}\right)$, and mesophyll efficiency $\left(\mathrm{Ci} / \mathrm{g}_{\mathrm{s}}\right)$ was observed at single leaf level.

Significant variations were observed in water use efficiency (WUE) and associated physiological traits like cumulative water transpired (CWT), net assimilation rate (NAR), mean transpiration rate (MTR), leaf area duration (LAD), and $\Delta^{13} \mathrm{C}$ in the population. The WUE ranges from 3.86 to $6.84 \mathrm{~g} / \mathrm{kg}$ with an average of $5.40 \mathrm{~g} / \mathrm{kg}$ and considerable transgressive segregation was observed. The variation in CWT was observed between 2.50 and $23.50 \mathrm{~kg} / \mathrm{plant}$. The average transpiration rate was $10.81 \mathrm{~L} /$ plant in the population. The NAR and MTR also varied with mean values of $13.07 \mathrm{mg} / \mathrm{dm}^{2}$ and $2.44 \mathrm{~mL} / \mathrm{dm}^{2}$ of leaf area, respectively. Similarly, the functional leaf area (LAD) varied between 1065.89 and $7992.77 \mathrm{dm}^{2} /$ day with mean leaf area duration of $4376.57 \mathrm{dm}^{2} /$ day. $\Delta^{13} \mathrm{C}$ also varied between 19.75 and $26.53 \% 0$ with a mean of $21.80 \%$ (Table 2). The variation in WUE, CWT, $\Delta{ }^{13} \mathrm{C}$, and so forth, showed that traits are metric nature and mapping population could be utilized for the identification of marker linked to quantitative traits.

3.2. Association of Root with Other Physiological Traits. The plants with the higher root biomass showed higher total biomass and correlation between these two traits is highly significant $(r=0.968)$ (Figure 2). It signifies the importance of root system in determining the total dry matter by absorbing the water from sub-soil layers from its better root system compared to parental lines. Subsequently strong positive significant correlations were noticed between root weight and total transpiration $(r=0.940)$, CWT and MTR $(r=$ $0.524)$, and total dry matter and CWT $(r=0.970)$ (Figure 2), suggesting that maintaining canopy hydraulic conductance with high carbon assimilation is one of the drought tolerance mechanisms.

3.3. Relationship between WUE with Other Physiological Traits. Significant inverse relationship between WUE and $\Delta^{13} \mathrm{C}(r=-0.413)$ was observed (Figure 2). It suggests that $\Delta^{13} \mathrm{C}$ could be a strong surrogate measure for WUE even in mapping population. The relationship between CWT and WUE was poor, suggesting stomatal control of WUE in mapping population and, similarly, between root weight and WUE. However, significant negative relationship between MTR and WUE was observed $(r=-0.552)$ in mapping population (data not shown). This signifies the genetic nature of the coffee plants for its heritable conductance type. It suggests that stomatal factors regulate the WUE in these plants rather than photosynthetic efficiency (mesophyll factors).

3.4. Identification of Polymorphic RAPD and Microsatellite Primers in Parental Lines. The contrasting parental lines L1 

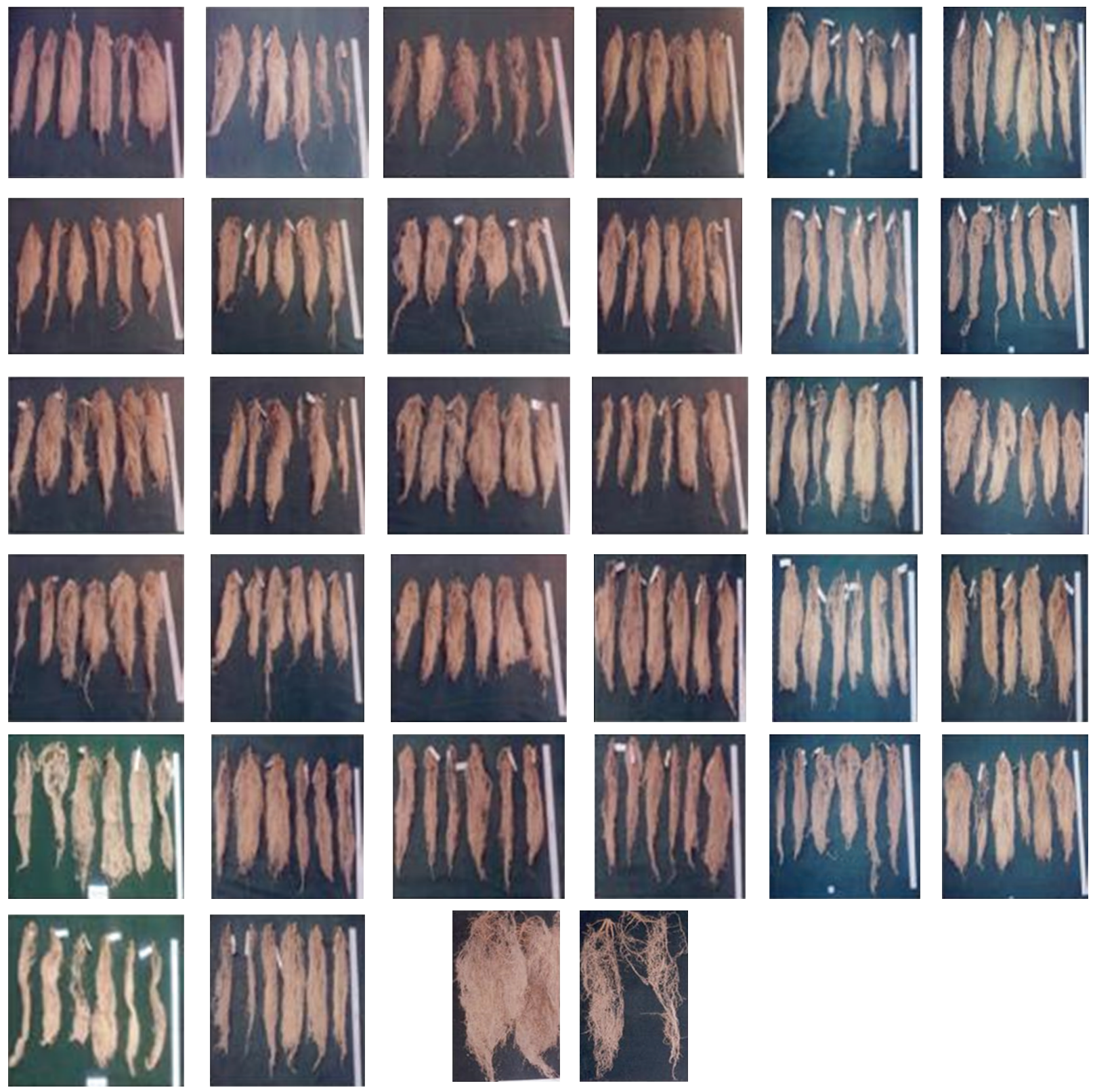

S.3334 L1valley
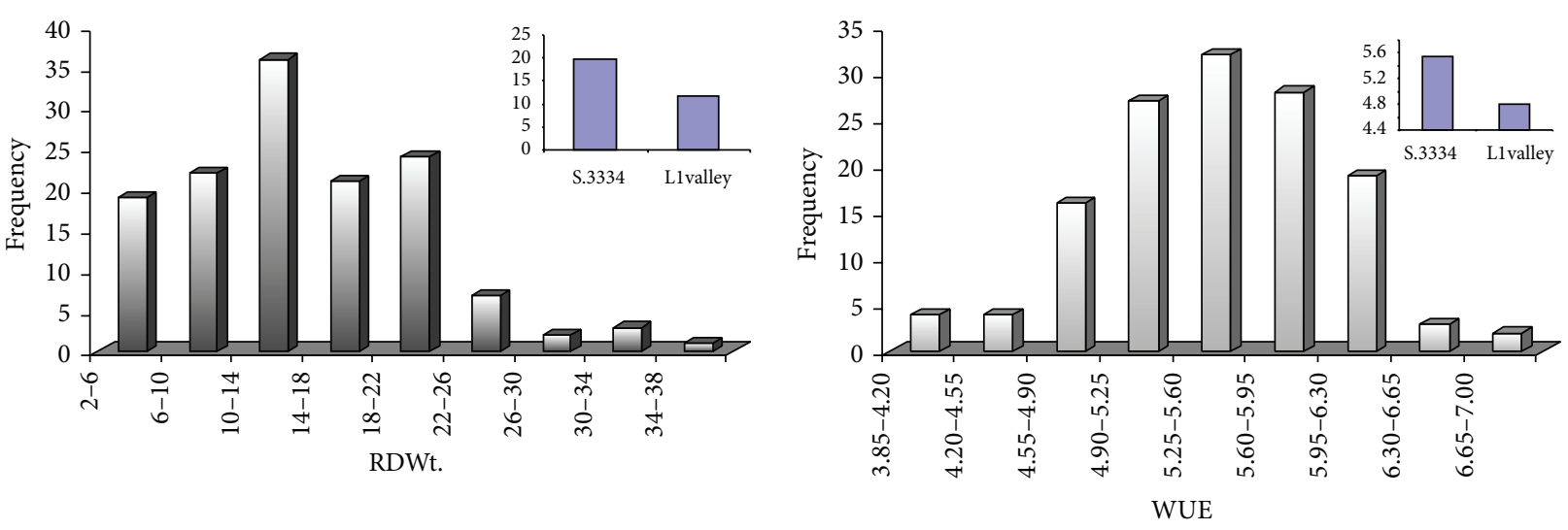

Figure 1: Continued. 

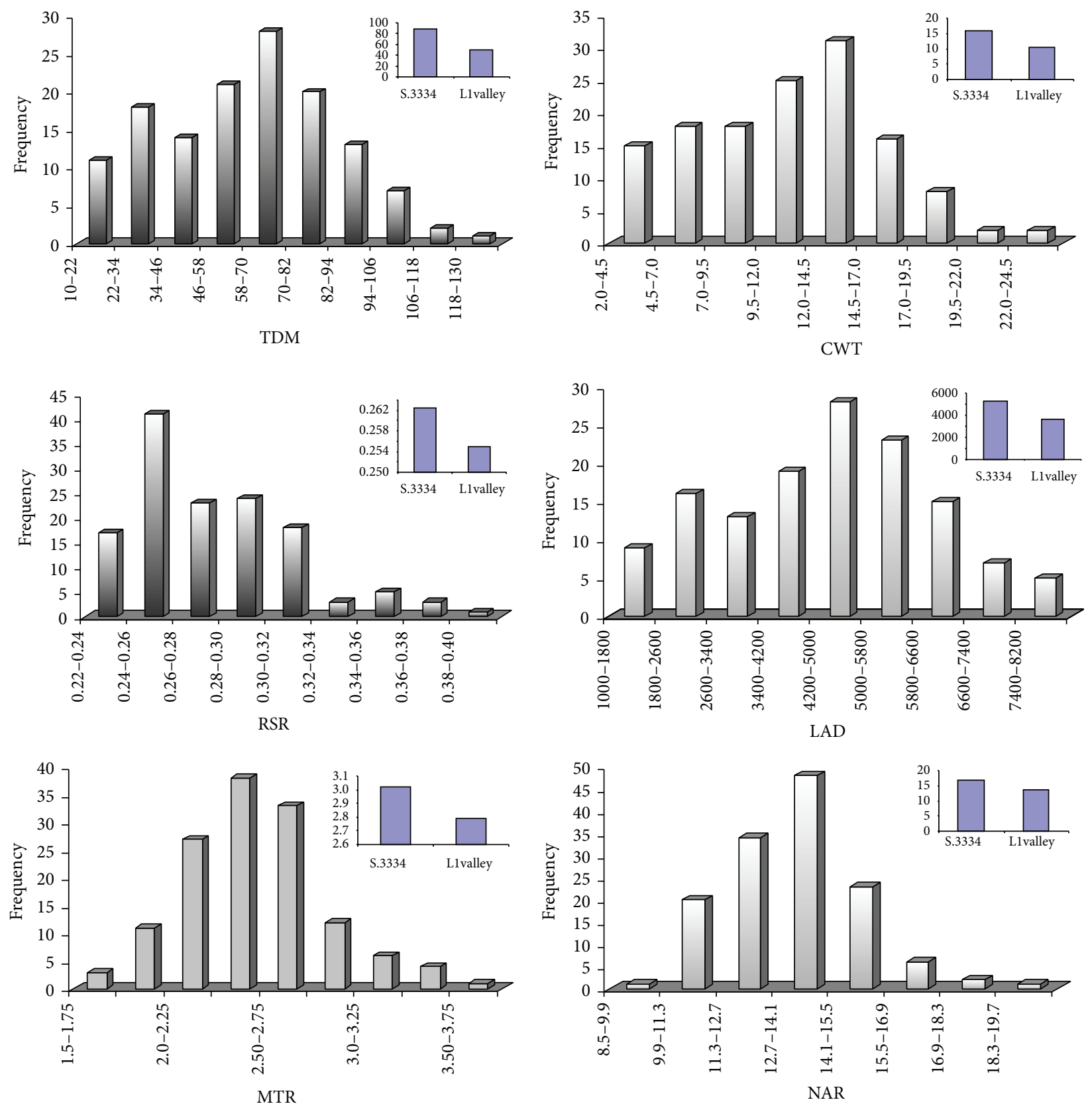

FIGURE 1: Genetic variability of root system and quantitative traits of mapping population of L1 valley $\times$ S.334.

valley (low root type) and S.3334 (high root type) were genotyped with 320 RAPD primers, of which 41 polymorphic primers generated 70 polymorphic loci (Table 3 ). Since RAPD is dominant marker, the PCR amplified DNA fragments were scored as dominant $(\mathrm{AA} / \mathrm{Aa})$, whereas absence of bands was scored as recessive (aa). We have analyzed our data within the framework of these assumptions.

Among them more than $85 \%$ of the primers produced single polymorphic locus and $15 \%$ of the primers yielded more than three polymorphic loci.

All the RAPD markers in the F1 generation of $C$. canephora segregated in ratios that were not consistent with Mendelian inheritance. The Chi-square tests were performed for each marker to determine segregation distortion from the expected allele frequency ratio of $1: 1$. At a significance level of $P=0.05$, about $62 \%$ of the marker loci were in agreement with the expected ratios and $38 \%$ of the marker loci were not following the Mendelian inheritance (Table 4). It is expected that RAPD bands of maternal DNA origin would show nonMendelian inheritance.

Besides RAPD marker system, 55 SSR markers were also used for genotyping; however, only nine primers showed polymorphism (Table 5), but did not follow the Mendelian segregation. The low level of DNA polymorphism between the two parental accessions, coupled with the large number of common bands, implies parental lines could be less diverse. 
TABLE 2: Range and mean values of the morphophysiological parameters in 134 F1 mapping population of Coffea canephora (L1 valley $\times$ S.3334).

\begin{tabular}{|c|c|c|c|c|c|}
\hline & Serial number & Parameters & Range & Mean & STDEV \\
\hline \multirow{4}{*}{ Root traits } & 1 & Root length $\left(\mathrm{cm}^{2}\right)$ & $41.5-83.0$ & 57.08 & 7.29 \\
\hline & 2 & Number of secondary roots & $2-60$ & 26.9 & 12.61 \\
\hline & 3 & Root dry weight (g/plant) & $2.57-34.69$ & 13.77 & 6.6 \\
\hline & 4 & Root : shoot ratio & $0.23-0.39$ & 0.27 & 0.03 \\
\hline \multirow{12}{*}{ Morphological traits } & 5 & Plant height $\left(\mathrm{cm}^{2}\right)$ & $13.5-105.3$ & 72.6 & 15.69 \\
\hline & 6 & Number of nodes & $11.0-42.0$ & 24.08 & 6.88 \\
\hline & 7 & Number of leaves & $2-70$ & 34.02 & 13.42 \\
\hline & 8 & Stem girth $(\mathrm{mm})$ & $5.88-13.65$ & 10.28 & 1.79 \\
\hline & 9 & Internodal length $(\mathrm{cm})$ & $1.9-12.5$ & 8.54 & 2 \\
\hline & 10 & Specific leaf dry weight $\left(\mathrm{mg} / \mathrm{dm}^{2}\right)$ & $1.41-2.64$ & 1.8 & 0.22 \\
\hline & 11 & Final leaf area $\left(\mathrm{cm}^{2}\right)$ & $1136.92-8190.61$ & 4491.19 & 1710.17 \\
\hline & 12 & Specific leaf area $(\mathrm{cm})$ & $378.99-710.97$ & 562.44 & 65.34 \\
\hline & 13 & Total leaf dry weight (g/plant) & $5.78-48.59$ & 26.02 & 10.43 \\
\hline & 14 & Stem dry weight (g/plant) & $4.81-52.62$ & 24.33 & 10.4 \\
\hline & 15 & Shoot dry weight (g/plant) & $10.59-96.64$ & 50.35 & 20.63 \\
\hline & 16 & Total dry matter (g/plant) & $11.6-121.43$ & 57.93 & 24.77 \\
\hline \multirow{6}{*}{ Gravimetric traits } & 17 & Leaf area duration ( $\mathrm{dm}^{2}$ days $)$ & $1065.89-7992.77$ & 4372.52 & 1658.04 \\
\hline & 18 & Net assimilation rate & $8.9-19.38$ & 13.07 & 1.71 \\
\hline & 19 & Cumulative water transpiration (lt/plant) & $2.5-23.5$ & 10.81 & 4.62 \\
\hline & 20 & Water use efficiency (g/kg) & $3.86-6.84$ & 5.4 & 0.58 \\
\hline & 21 & Mean transpiration rate $\left(\mathrm{mL} / \mathrm{dm}^{2}\right.$ days $)$ & $1.5-3.52$ & 2.44 & 0.38 \\
\hline & 22 & Delta 13c (mill) & $19.75-26.53$ & 21.8 & 1.11 \\
\hline \multirow{7}{*}{ Gas exchange parameters } & 23 & Photosynthesis (Pn). (mmol/m²/S) & $5.45-27.27$ & 16.9 & 3.91 \\
\hline & 24 & Transpiration rate $(E)\left(\mathrm{mg} / \mathrm{m}^{2} / \mathrm{s}\right)$ & $0.71-7.47$ & 3.38 & 1.34 \\
\hline & 25 & Conductance $\left(\mathrm{g}_{\mathrm{s}}\right)\left(\mathrm{mmol} / \mathrm{m}^{2} / \mathrm{s}\right)$ & $0.05-1$ & 0.35 & 0.17 \\
\hline & 26 & $\mathrm{Ci} / \mathrm{g}_{\mathrm{s}}$ & $288.76-3484.25$ & 859.3 & 405.1 \\
\hline & 27 & $\mathrm{Ci}$ & $186.5-296.67$ & 247.98 & 24.88 \\
\hline & 28 & $\mathrm{~A} / \mathrm{g}_{\mathrm{s}}$ & $24.06-93.26$ & 54.42 & 15.52 \\
\hline & 29 & $\mathrm{~A} / E$ & $2.63-14.07$ & 5.52 & 1.76 \\
\hline
\end{tabular}

TABLE 3: Polymorphic RAPD primers and their sequences used to study the segregation of markers in the mapping population.

\begin{tabular}{|c|c|c|c|c|c|c|c|c|}
\hline $\begin{array}{l}\text { Polymorphic } \\
\text { bands }\end{array}$ & $\begin{array}{c}\text { Primer } \\
\text { name }\end{array}$ & Sequence & $\begin{array}{c}\text { Primer } \\
\text { name }\end{array}$ & Sequence & $\begin{array}{c}\text { Primer } \\
\text { name }\end{array}$ & Sequence & $\begin{array}{c}\text { Primer } \\
\text { name }\end{array}$ & Sequence \\
\hline \multirow{5}{*}{1} & OPK18 & CCTAGTCGAG & OPN6 & GAGACGCACA & OPQ5 & CCGCGTCTTG & OPV5 & TCCGAGAGGG \\
\hline & OPK19 & CACAGGCGGA & OPO1 & GGCACGTAAG & OPS1 & CTACTGCGCT & OPW9 & GTGACCGAGT \\
\hline & OPK20 & GTGTCGCGAG & OPO18 & CTCGCTATCC & OPV11 & CTCGACAGAG & OPY20 & AGCCGTGGAA \\
\hline & OPM5 & GGGAACGTGT & OPO4 & AAGTCCGCTC & OPV14 & AGATCCCGCC & OPZ11 & CTCAGTCGCA \\
\hline & OPN19 & GTCCGTACTG & OPP2 & TCGGCACGCA & OPV2 & AGTCACTCCC & & \\
\hline \multirow{4}{*}{2} & OPK10 & GTGCSSCGTG & OPL18 & ACCACCCACC & OPO16 & TCGGCGGTTC & OPT7 & GTCCATGCCA \\
\hline & OPK11 & AATGCCCCAG & OPM11 & GTCCACTGTG & OPP5 & CCCCGGTAAC & OPU1 & ACGGACGTCA \\
\hline & OPL1 & GGCATGACCT & OPM17 & TCAGTCCGGG & OPQ20 & TCGCCCAGTC & OPW17 & GTCCTGGGTT \\
\hline & OPL12 & GGGCGGTACT & OPO10 & TCAGAGCGCC & OPR4 & CCCGTAGCAC & OPZ3 & CAGCACCGCA \\
\hline \multirow{2}{*}{3} & OPL19 & GAGTGGTGAC & OPM2 & ACAACGCCTC & OPP11 & AACGCGTCGG & OPP9 & GTGGTCCGCA \\
\hline & OPZ10 & CCGACAAACC & & & & & & \\
\hline 4 & OPK17 & CCCAGCTGTG & & & & & & \\
\hline
\end{tabular}




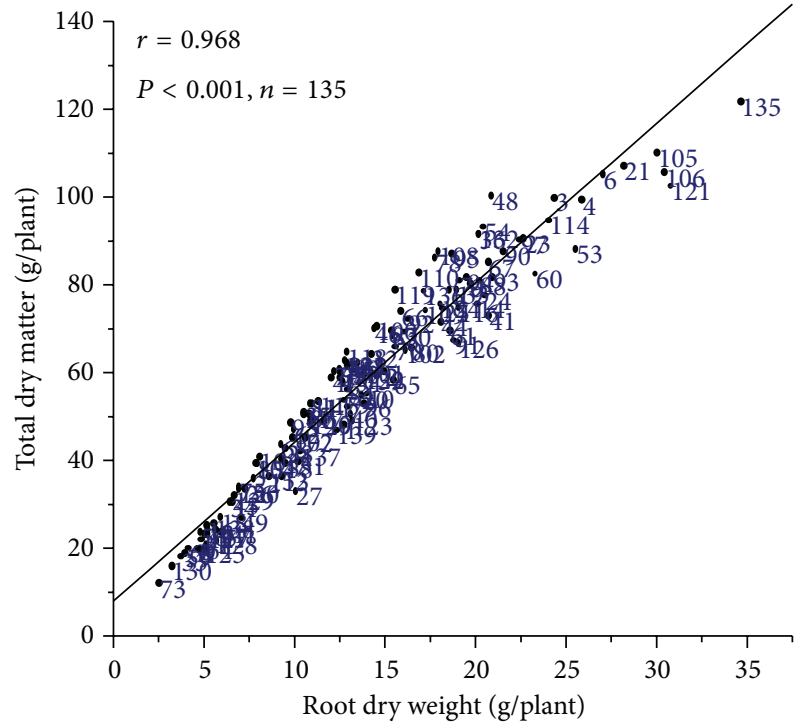

(a)

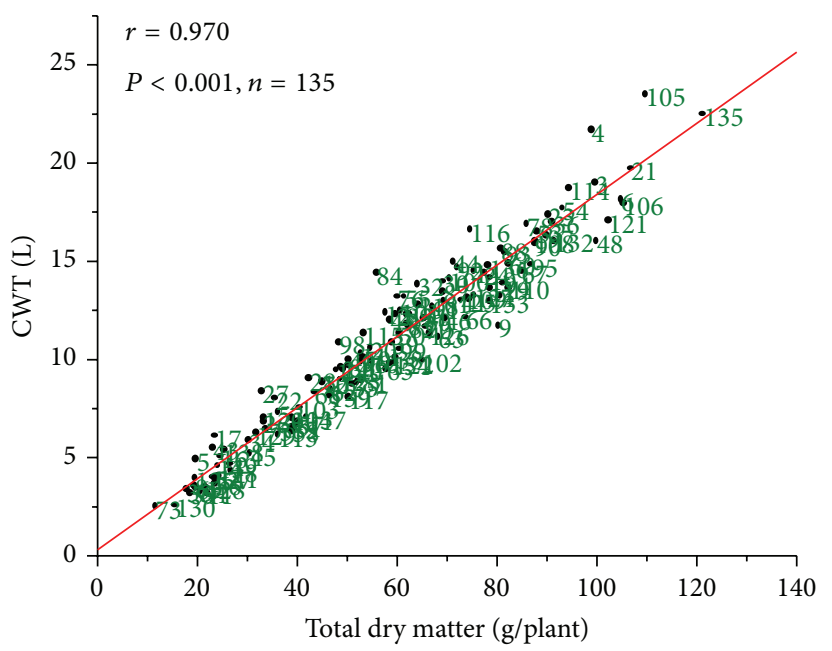

(c)

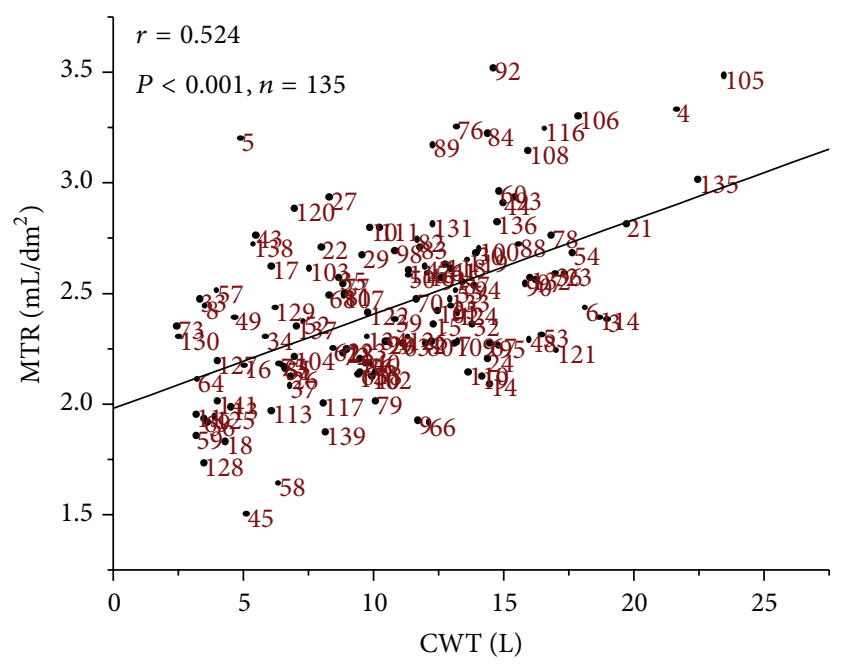

(e)

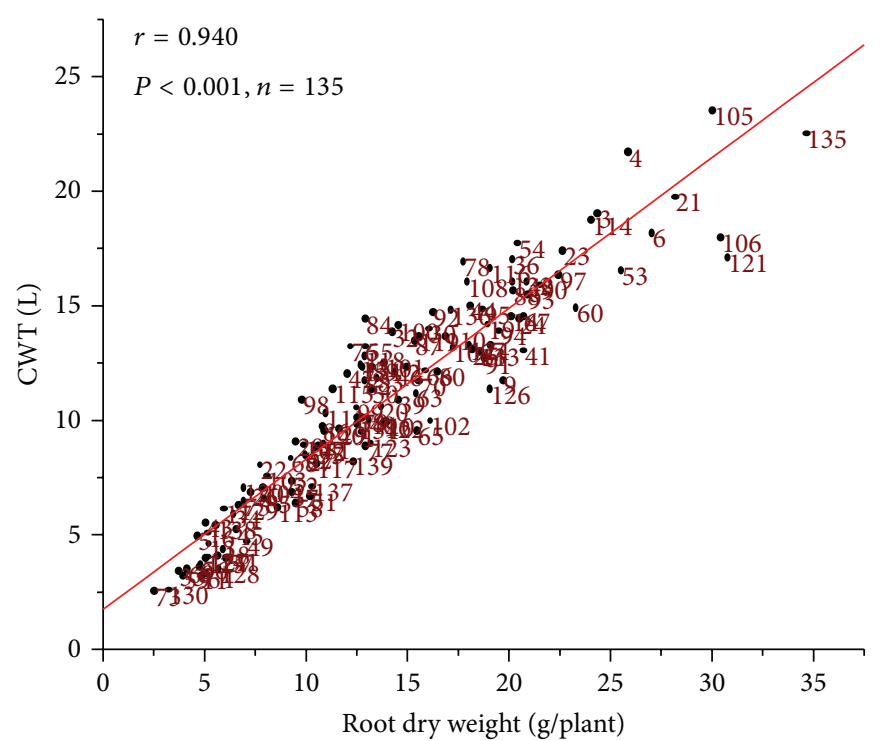

(b)

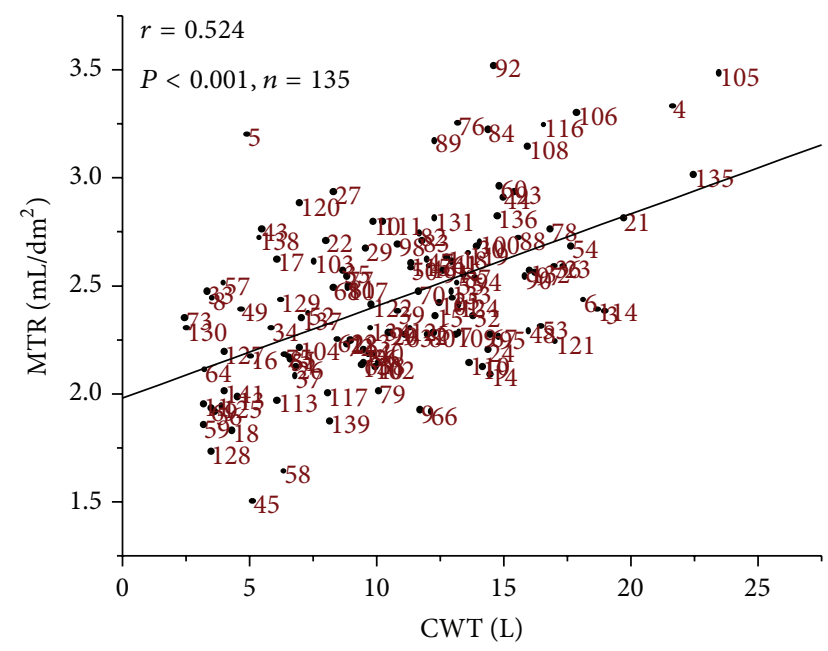

(d)

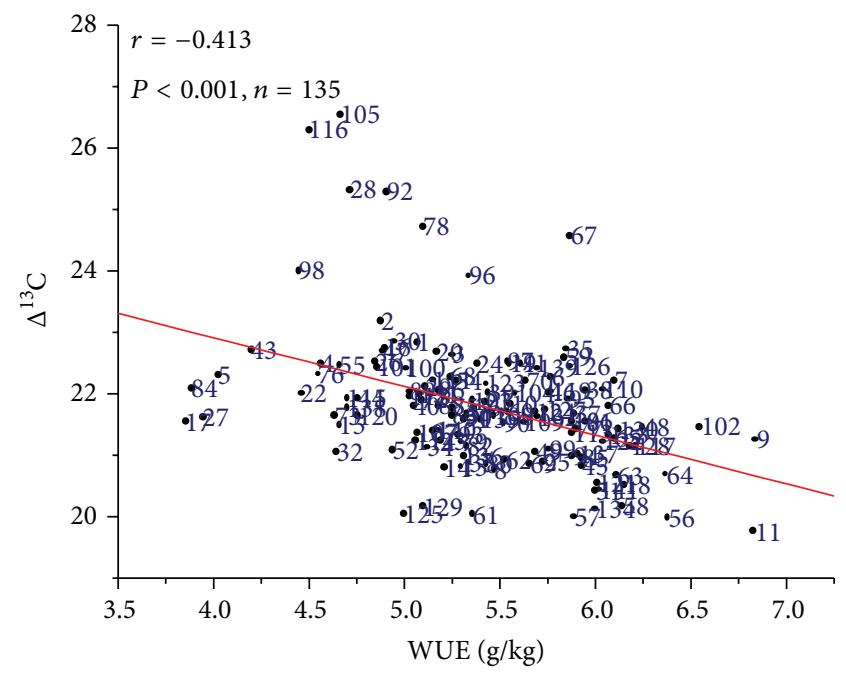

(f)

Figure 2: Relationship between the RDW/TDM, RDW/CWT, TDM/CWT, CWT/MTR, CWT/MTR, and WUE/ $\Delta^{13} \mathrm{C}$ in the mapping population of C. canephora $(\mathrm{Ll}$ valley $\times$ S.334). 
TABLE 4: Chi-square tests $\left(\chi^{2}\right)$ for RAPD and SSR markers in the Coffea canephora mapping population.

\begin{tabular}{|c|c|c|c|c|c|c|c|c|}
\hline \multirow{2}{*}{ Parents } & \multirow{2}{*}{$\begin{array}{c}\mathrm{F} 1 \\
\text { progenies }\end{array}$} & \multirow{2}{*}{$\begin{array}{l}\text { Marker } \\
\text { system }\end{array}$} & \multirow{2}{*}{$\begin{array}{l}\text { Total polymor- } \\
\text { phic markers }\end{array}$} & \multirow{2}{*}{$\begin{array}{l}\text { Marker loci not } \\
\text { following expected ratio }\end{array}$} & \multirow{2}{*}{$\begin{array}{l}\text { Marker loci following } \\
\text { expected ratio }\end{array}$} & \multicolumn{3}{|c|}{ Number of significant markers } \\
\hline & & & & & & $P=0.95$ & $P=0.05$ & $P=0.001$ \\
\hline \multirow{2}{*}{$\begin{array}{l}\text { L1 valley } \times \\
\text { S.3334 }\end{array}$} & \multirow{2}{*}{134} & RAPD & 70 & 28 & $42(1: 1)$ & 32 & 3 & 7 \\
\hline & & SSR & 9 & 9 & $0(3: 1)$ & - & - & - \\
\hline
\end{tabular}

TABLE 5: Polymorphic microsatellite primers and their sequences used to study the segregation of markers in the mapping population.

\begin{tabular}{|c|c|c|c|c|}
\hline Serial number & Primer & Sequence & $\operatorname{Tm}\left({ }^{\circ} \mathrm{C}\right)$ & Size range \\
\hline \multirow{2}{*}{1} & \multirow{2}{*}{ CM11 } & F: GCTGCCAGAAAAATGTTGCAGTG & \multirow{2}{*}{58} & \multirow{2}{*}{$270-338$} \\
\hline & & R: CTGCCTCGTAAAAGCTTGCGTTG & & \\
\hline \multirow{2}{*}{2} & \multirow{2}{*}{ CM13 } & F: GCTATGCAGCTTGTTCGCAATCC & \multirow{2}{*}{59} & \multirow{2}{*}{$350-411$} \\
\hline & & R: CCAGCTATATCAGGAGCAGAACC & & \\
\hline \multirow{2}{*}{3} & \multirow{2}{*}{ CM180 } & F: CATGTGTAATACATTCAACAGTGA & \multirow{2}{*}{60} & \multirow{2}{*}{$300-350$} \\
\hline & & R: GCAATAGTGGTTGTCATCCTT & & \\
\hline \multirow{2}{*}{4} & \multirow{2}{*}{ CM32 } & F: AACTCTCCATTCCCGCATTC & \multirow{2}{*}{60} & \multirow{2}{*}{$180-200$} \\
\hline & & R: CTGGGTTTTCTGTGTTCTCG & & \\
\hline \multirow{2}{*}{5} & \multirow{2}{*}{ CM46 } & F: CAGCTAGTGTGAAGGGAAAC & \multirow{2}{*}{55} & \multirow{2}{*}{$300-350$} \\
\hline & & R: GTTATCATGGTCTTACACG & & \\
\hline \multirow{2}{*}{6} & \multirow{2}{*}{ CM20 } & F: CTTGTTTGAGTCTGTCGCTG & \multirow{2}{*}{60} & \multirow{2}{*}{$250-300$} \\
\hline & & R: TTTCCCTCCCAATGTCTGTA & & \\
\hline \multirow{2}{*}{7} & \multirow{2}{*}{ CM171 } & F: TTCССССАТСТTТTТСТTТC & \multirow{2}{*}{60} & \multirow{2}{*}{$250-300$} \\
\hline & & R: TTGTATACGGCTCGTCAGGT & & \\
\hline \multirow{2}{*}{8} & \multirow{2}{*}{ CM166 } & F: AAGAGGTGCCTATCACCGTC & \multirow{2}{*}{60} & \multirow{2}{*}{$230-260$} \\
\hline & & R: CGAGGTATCAAAAAGCACCT & & \\
\hline \multirow{2}{*}{9} & \multirow{2}{*}{ CM211 } & F: TCATGCCAAATATGAGTGGA & \multirow{2}{*}{60} & \multirow{2}{*}{$300-350$} \\
\hline & & R: GAGATGGCAAAGGCTGTTC & & \\
\hline
\end{tabular}

3.5. Single Marker Analysis for Root and Associated Physiological Traits. Complex physiological traits have been described by a small number of major QTL [24], but it is intricate to find useful QTL for a particular trait, as their individual contribution is smaller. Therefore under such condition Single Marker Analysis (SMA) is generally a good choice when the goal is simply a detection of marker locus linked to a trait. However, estimation of its position and its effects requires further complex analysis such as marker regression [25] or interval analysis [26].

In our study Single Marker ANOVA is used to identify markers showing significant association with 29 morphophysiological traits (SAS software with $P \leq 0.05$ ).

In the single marker analysis, simple regression model was examined to study the association between marker loci (independent) and trait score (dependent variable) and also computed the percent phenotypic variance explained by each marker. Seventy polymorphic marker loci were employed for simple regression analysis; however, it was discovered that 37 RAPD and 5 SSR markers explained their association with morphophysiological traits.

3.6. Markers Linked to Root Traits. The single marker analysis revealed four markers such as OPS1 ${ }_{850}, \mathrm{OPK}_{11}$, OPY20 ${ }_{1200}$, $\mathrm{OPZ10}_{1350}$, and $\mathrm{CM}_{13} 3_{400}$ were significantly associated with root length $(P=0.05)$ and explained phenotypic variance of $4.41 \%, 2.95 \%, 3.56 \%, 5.12 \%$, and $5.12 \%$, respectively.
A number of secondary roots linked to three markers such as $\mathrm{OPO}_{450}(4.40 \%), \mathrm{OPK}_{10} 1_{1000}(5.51 \%)$, and OPV14 (5.82\%) were significantly $(P=0.05)$ associated. Similarly six markers such as OPK11 $1000(3.26 \%)$, OPP9 $_{1030}(3.5 \%)$, $\mathrm{OPM}_{600}$ (3.75\%), OPL19 900 (5.61\%), OPL19 600 (4.11\%), $\mathrm{OPR}_{600}(3.30 \%)$, and $\mathrm{CM} 211_{300}\left(R^{2}=4.96 \%\right)$ revealed significant $(P=0.05)$ association with the root to shoot ratio (Table 6 ). This implies the root associated traits are polygenic controlling many genes. However, root dry weight is associated with only one maker $\mathrm{OPL1}_{1400}(4.86 \%)$.

3.7. Markers Linked to Morphophysiological Traits. Besides root traits, polygenic inheritance traits such as morphological, gravimetric, and gas exchange at single leaf level traits were also deployed for marker trait association. Single marker analysis revealed more than three markers linked to each trait and 25 markers are colocalized with more than one trait and 17 markers are associated with single trait (Table 7). The marker OPP5 ${ }_{1800}$ is coassociated with shoot dry weight and leaf area duration (LAD), and these two traits are positively correlated $\left(R^{2}=0.93\right)$. Four markers $\left(\mathrm{OPL1}_{1450}\right.$, $\mathrm{OPL1}_{1650}, \mathrm{OPM17}_{1400}$, and OPK20 350 ) linked to NAR and two markers OPR4 600 and OPL12 2000 are significantly $(P=$ 0.01 ) associated with cumulative water transpired (CWT).

The ${ }^{13} \Delta \mathrm{C}$ is the surrogate method to quantify the water use efficiency and it was demonstrated that there is inverse 
TABLE 6: RAPD markers linked to root traits in the mapping population of C. canephora (L1 valley $\times$ S.3334).

\begin{tabular}{lccc}
\hline Trait & Marker & $R^{2}(\%)$ & $P<0.05$ \\
\hline \multirow{4}{*}{ Root length } & OPY20 $_{1200}$ & 2.95 & 0.0449 \\
& OPZ10 $_{1350}$ & 3.56 & 0.0286 \\
& OPK11 $_{780}$ & 4.41 & 0.0178 \\
& OPS1 $_{850}$ & 6.86 & 0.0001 \\
& CPCM13 $_{400}$ & 5.12 & 0.0105 \\
\hline \multirow{3}{*}{ Number of secondary roots } & OPO16 $_{450}$ & 4.4 & 0.0179 \\
& OPK11 $_{1000}$ & 5.51 & 0.0059 \\
& OPV14 $_{550}$ & 5.82 & 0.0042 \\
\hline Root dry weight & OPL1 $_{1450}$ & 4.76 & 0.0073 \\
\hline \multirow{4}{*}{ Root to shoot ratio } & OPK11 $_{1000}$ & 3.26 & 0.038 \\
& OPR4 $_{600}$ & 3.3 & 0.0367 \\
& OPP9 $_{1030}$ & 3.5 & 0.0288 \\
& OPM11 $_{600}$ & 3.75 & 0.0267 \\
& OPL19 $_{600}$ & 4.11 & 0.0223 \\
& OPL19 $_{900}$ & 5.61 & 0.0062 \\
CM211 $_{300}$ & 4.96 & 0.0105 \\
\hline
\end{tabular}

relationship between these two traits. Of the six associated markers, OPZ10 ${ }_{1350}$ was found to be associated with ${ }^{13} \Delta \mathrm{C}$ and WUE with phenotypic variance of $4.12 \%$ and $3.02 \%$, respectively. This marker locus could be negative additive effect since traits are negatively related. The mesophyll efficiency $\left(\mathrm{Ci} / \mathrm{g}_{\mathrm{s}}\right)$, intrinsic WUE $\left(\mathrm{A} / \mathrm{g}_{\mathrm{s}}\right)$, and photosynthetic rate $(\mathrm{Pn})$ are, respectively, associated with $\mathrm{CM}_{13}{ }_{400}(4.83 \%), \mathrm{CM}_{171} 1_{210}$ (3.45\%), and $\mathrm{CM} \mathrm{I}_{190}$ (3.72\%) (Table 7). Whereas positively related traits are associated with the same marker such as $\mathrm{OPP}_{1800}$ (LAD and shoot dry weight), OPZ10 ${ }_{1030}$ (MTR and $\mathrm{g}_{\mathrm{s}}$ ), and $\mathrm{OPK} 20_{350}(\mathrm{Ci}$ and NAR) alleles contribution from S.3334. The markers linked to other gas exchange parameters were given in Table 7, which are contributed from S.3334.

\section{Discussion}

We developed a F1 mapping population by crossing contrasting root traits S.3334 high root type as male and L1 valley low root type as female to identify makers linked to root traits and water use efficient types. However, in annual crops, $\mathrm{F}_{2}$, recombinant inbred lines (RILs), near isogenic lines (NILs), and doubled haploids (DH) mapping population will be used to associate markers with the trait of our interest. However, in perennials the germplasm lines and the cultivated accessions are often highly heterozygous; consequently $\mathrm{F}_{1}$ population developed from heterozygous parents was used in this study and showed considerable phenotypic and genetic variations.

One of the objectives of studying the mapping population was to score the variability in roots and other physiological traits under drought and thus mapping population was gown up in $70 \%$ FC of water stress to study the heritability of root traits. Indeed root traits are highly complex genetic mechanism, controlled by multi genes and highly heritable in water non limiting environment [27]. The results demonstrated significant variability was observed in root dry weight (RDW), total dry matter (TDM), root to shoot ratio (RSR), cumulative water transpired (CWT) with considerable transgressive segregation (Figure 1), and quantitative inheritance of drought tolerance [28]. However, significant positive correlation between RDW/TDM, RDW/CW, and TDM/CWT indicates that under drought increased root growth maintains the shoot hydraulic conductance as adoptive strategy $[29,30]$. The decreased mean transpiration (MTR) and increased water use efficiency (WUE) could be due to decreased stomatal aperture through chemical signals such as ABA [31]. However, some of the clones showed that increased MTR with increased CWT would favor the stomatal conductance and net photosynthesis. Such clones are better for breeding drought tolerance. Inverse relationship between $\Delta^{13} \mathrm{C}$ and WUE in robusta coffee accessions was observed (Figure 2), thus measuring $\Delta^{13} \mathrm{C}$ which can be a surrogate method to identify best WUE types clones in breeding $[19,32]$. Breeding for such quantitative traits is highly complex cumbersome and thus by determining the allele of a DNA marker, plants that possess particular genes or quantitative trait loci (QTLs) are better than their phenotype. With this background effort was made to identify the markers linked to root and associated physiological traits in Coffea canephora.

Despite the efforts, no successful linkage map could be obtained, partly due to the inadequate number of polymorphic markers generated from this study. The output of the association analysis indicates that, out of 29 traits, only 24 traits were linked to 85 markers. Even markers linked to traits explaining the phenotypic variation were not more than $10 \%$. In the present study, phenotypic variation explanation for all the traits ranges from 2.61 to $9.86 \%$. This suggests that the successful application of molecular markers in trait mapping greatly requires more polymorphic markers, while successful mapping attempts could still be carried out in the absence of a linkage map as done in chickpea [33]. Although construction of linkage map was done in C. arabica [34] and C. canephora [35] predominantly using AFLP and RAPD markers, association with the traits was not attempted. Similarly the first molecular linkage map generated using pseudo testcross strategy for Coffea canephora $(\mathrm{CxR} \times$ Kagnalla) has the largest number of mapped SSRs (71 genomic, including nine EST-SSRs) [36], but trait association was not correlated.

Most of the markers explained phenotypic variance between 3 and 4\%; however, only two markers, that is, OPZ11 $_{1500}$ and OPV14 $4_{500}$, were significantly $(P<0.01)$ linked to photosynthetic rate $(\mathrm{Pn})$, accounting the variation of about $9.23 \%$ and $9.30 \%$, respectively (Table 7 ). The root traits such as root length, number of secondary roots, root dry weight, and root: shoot ratio, revealed significant association $(P<$ 0.05 ) with markers and the variability ranges from 2.95 to $6.86 \%$ (Table 6). This suggests the trait variability explanation is not sufficient to answer the probabilities of occurrence of these markers due to limited polymorphic markers.

In the present study, codominant SSR markers were also used for the marker-trait association study. The SSR markers identified herein are significantly associated with morphological and physiological traits, but these markers 
TABLE 7: List of RAPD and SSR markers overlapped with more than one trait.

\begin{tabular}{|c|c|c|c|c|c|}
\hline Markers & Traits & $\begin{array}{c}R^{2}(\%) \\
(P<0.05)\end{array}$ & Markers & Traits & $\begin{array}{c}R^{2} \% \\
(P<0.05)\end{array}$ \\
\hline \multirow{4}{*}{ OPK11 $1_{1000}$} & Internodal length & 4.74 & \multirow{4}{*}{$\begin{array}{l}\mathrm{OPR}_{600} \\
\mathrm{OPR}_{750}\end{array}$} & CWT & 5.08 \\
\hline & Root to shoot ratio & 3.26 & & RSR & 3.30 \\
\hline & Number of secondary roots & 5.51 & & Number of leaves & 5.65 \\
\hline & Stem dry weight & 3.44 & & $\mathrm{~g}_{\mathrm{s}}$ & 2.93 \\
\hline \multirow{2}{*}{ OPK18 $8_{1200}$} & Specific leaf area & 4.70 & \multirow{2}{*}{$\mathrm{OPV}_{14}{ }_{550}$} & Pn & 9.30 \\
\hline & Plant height & 4.51 & & Number of secondary Roots & 5.82 \\
\hline \multirow{2}{*}{$\mathrm{OPK}_{19}{ }_{2000}$} & Photosynthetic rate $(\mathrm{Pn})$ & 5.55 & \multirow{2}{*}{ OPY20 ${ }_{1200}$} & WUE & 3.10 \\
\hline & WUE & 4.43 & & Plant height & 4.23 \\
\hline \multirow{3}{*}{$\mathrm{K} 20_{350}$} & NAR & 4.82 & \multirow{3}{*}{$\mathrm{OPZ}_{11} 1_{1500}$} & Number of leaves & 3.99 \\
\hline & WUE & 4.45 & & Root length & 2.95 \\
\hline & $\mathrm{Ci}$ & 4.32 & & Pn & 9.23 \\
\hline \multirow{6}{*}{$\mathrm{OPL1}_{1400}$} & Plant height & 5.77 & \multirow{6}{*}{$\begin{array}{l}\mathrm{OPZ10}_{1350} \\
\mathrm{OPZ10}_{1030}\end{array}$} & MTR & 8.21 \\
\hline & Internodal length & 3.81 & & ${ }^{13} \Delta \mathrm{C}$ & 4.12 \\
\hline & NAR & 4.27 & & Plant height & 3.03 \\
\hline & Shoot dry weight & 4.00 & & Root length & 3.56 \\
\hline & Root dry weight & 4.76 & & WUE & 3.02 \\
\hline & Pn & 2.61 & & $\mathrm{Ci} / \mathrm{g}_{\mathrm{s}}$ & 5.09 \\
\hline \multirow{2}{*}{ OPL12 2000} & Plant height & 3.68 & \multirow{6}{*}{$\mathrm{OPZ10} 0_{720}$} & $\mathrm{Pn}$ & 7.56 \\
\hline & CWT & 4.74 & & MTR & 4.38 \\
\hline \multirow{2}{*}{$\mathrm{OPL}_{12}{ }_{1650}$} & ${ }^{13} \Delta \mathrm{C}$ & 3.61 & & $g_{s}$ & 2.96 \\
\hline & $\mathrm{pn}$ & 3.07 & & $\mathrm{~g}_{\mathrm{s}}$ & 3.26 \\
\hline \multirow{2}{*}{$\mathrm{OPL}_{1000}$} & Number of nodes & 7.78 & & Pn & 3.14 \\
\hline & LAD & 3.82 & & Internodal length & 3.58 \\
\hline \multirow{2}{*}{ OPL19 $_{900}$} & SLW & 3.33 & \multirow{2}{*}{$\mathrm{CPCM}_{450}$} & Root length & 5.12 \\
\hline & RSR & 3.60 & & $\mathrm{Ci} / \mathrm{g}_{\mathrm{s}}$ & 4.83 \\
\hline \multirow{3}{*}{$\mathrm{OPM}_{600}$} & $\mathrm{~A} / \mathrm{g}_{\mathrm{s}}$ & 3.85 & \multirow{3}{*}{$\begin{array}{l}\mathrm{CM} 171_{300} \\
\mathrm{CM}_{166_{260}}\end{array}$} & Stem girth & 4.54 \\
\hline & RSR & 4.11 & & $\mathrm{~A} / \mathrm{g}_{\mathrm{s}}$ & 3.45 \\
\hline & MTR & 2.94 & & No. of nodes & 3.93 \\
\hline \multirow{2}{*}{$\mathrm{OPO}_{1400}$} & $\mathrm{Ci}$ & 3.13 & \multirow{8}{*}{$\mathrm{CM} 211_{300}$} & SLA & 7.19 \\
\hline & $\mathrm{E}$ & 3.18 & & $E$ & 4.18 \\
\hline \multirow{3}{*}{$\mathrm{OPP}_{1800}$} & LAD & 3.82 & & SLW & 2.83 \\
\hline & Internodal length & 5.82 & & RSR & 4.96 \\
\hline & Shoot dry weight & 2.71 & & $E$ & 4.23 \\
\hline \multirow{3}{*}{$\mathrm{OPP9}_{1030}$} & $\mathrm{Ci} / \mathrm{g}_{\mathrm{s}}$ & 6.12 & & & \\
\hline & SLW & 3.33 & & & \\
\hline & RSR & 3.50 & & & \\
\hline
\end{tabular}

were explaining the trait in the range between $2.83 \%$ and $7.19 \%$. This study has provided more detailed information of root and associated physiological traits relationships under drought and identification of markers linked to such traits with the limited polymorphic markers by employing Single Marker Analysis (SMA). QTL maps could be used to for long-term, drought breeding. Further studies are needed to confirm the estimation of QTL positions and effects and to validate markers prior to routine marker assisted selection for drought tolerance in coffee.

\section{Conflict of Interests}

The authors declare that there is no conflict of interests regarding the publication of this paper.

\section{References}

[1] F. M. DaMatta, "Exploring drought tolerance in coffee: a physiological approach with some insights for plant breeding," Brazilian Journal of Plant Physiology, vol. 16, no. 1, pp. 1-6, 2004. 
[2] M. Nesbitt, The Cultural History of Plants, Taylor \& Francis, 2005.

[3] F. M. Damatta, "Drought as a multidimensional stress affecting photosynthesis in tropical tree crops," in Advances in Plant Physiology, A. Hemantaranjan, Ed., vol. 5, pp. 227-265, 2003.

[4] K. Harovon Mogel, "Genotype $\times$ environment $\times$ management: interactions key to beating future droughts," CSA News, vol. 58, pp. 4-9, 2013.

[5] F. M. DaMatta, A. R. M. Chaves, H. A. Pinheiro, C. Ducatti, and M. E. Loureiro, "Drought tolerance of two field-grown clones of Coffea canephora," Plant Science, vol. 164, no. 1, pp. 111-117, 2003.

[6] H. A. Pinheiro, F. M. DaMatta, A. R. M. Chaves, M. E. Loureiro, and C. Ducatti, "Drought tolerance is associated with rooting depth and stomatal control of water use in clones of Coffea canephora," Annals of Botany, vol. 96, no. 1, pp. 101-108, 2005.

[7] J. B. Passioura, "Phenotyping for drought tolerance in grain crops: when is it useful to breeders?" Functional Plant Biology, vol. 39, no. 11, pp. 851-859, 2012.

[8] J. S. Sperry, "Hydraulics of vascular water transport," in Mechanical Integration of Plant Cells and Plants, P. Wojtaszek, Ed., vol. 9 of Signaling and Communication in Plants, pp. 303-327, Springer, Berlin, Germany, 2011.

[9] A. P. Wasson, R. A. Richards, R. Chatrath et al., "Traits and selection strategies to improve root systems and water uptake in water-limited wheat crops," Journal of Experimental Botany, vol. 63, no. 9, pp. 3485-3498, 2012.

[10] G. D. Herder, G. van Isterdael, T. Beeckman, and I. de Smet, "The roots of a new green revolution," Trends in Plant Science, vol. 15, no. 11, pp. 600-607, 2010.

[11] H. T. Nguyen, R. C. Babu, and A. Blum, "Breeding for drought resistance in rice: physiology and molecular genetics considerations," Crop Science, vol. 37, no. 5, pp. 1426-1434, 1997.

[12] A. Blum, Plant Breeding for Water-Limited Environments, Springer Science+Business Media LLC, New York, NY, USA, 2011.

[13] L. B. Motta, T. C. B. Soares, M. A. G. Ferrão, E. T. Caixeta, R. M. Lorenzoni, and J. D. de Souza Neto, "Molecular characterization of arabica and Conilon coffee plants genotypes by SSR and ISSR markers," Brazilian Archives of Biology and Technology, vol. 57, no. 5, pp. 728-735, 2014.

[14] P. Marraccini, L. P. Freire, G. S. C. Alves et al., " $R B C S 1$ expression in coffee: Coffea orthologs, Coffea arabica homeologs, and expression variability between genotypes and under drought stress," BMC Plant Biology, vol. 11, article 85, 2011.

[15] P. Marraccini, F. Vinecky, G. S. C. Alves et al., "Differentially expressed genes and proteins upon drought acclimation in tolerant and sensitive genotypes of Coffea canephora," Journal of Experimental Botany, vol. 63, no. 11, pp. 4191-4212, 2012.

[16] F. Denoeud, L. Carretero-Paulet, A. Dereeper et al., "The coffee genome provides insight into the convergent evolution of caffeine biosynthesis," Science, vol. 345, no. 6201, pp. 1181-1184, 2014.

[17] A. Dereeper, S. Bocs, M. Rouard et al., "The coffee genome hub: a resource for coffee genomes," Nucleic Acids Research, vol. 43, no. 1, pp. D1028-D1035, 2015.

[18] M. Udayakumar, M. S. Sheshshayee, K. N. Nataraj et al., "Why has breeding for water use efficiency not been successful? An analysis and alternate approach to exploit this trait for crop improvement," Current Science, vol. 74, no. 11, pp. 1000-1003, 1998.

[19] M. G. Awati, Genetic diversity and molecular markers for root and associated physiological traits of Robusta (coffea canephora Pierre ex. F.) accessions [Ph.D. thesis], University of Agricultural Sciences, Bangalore, India, 2005.
[20] C. E. Williams and P. C. Ronald, "PCR template-DNA isolated quickly from monocot and dicot leaves without tissue homogenization," Nucleic Acids Research, vol. 22, no. 10, pp. 1917-1918, 1994.

[21] S. D. Tanksley, "Mapping polygenes," Annual Review of Genetics, vol. 27, no. 1, pp. 205-233, 1993.

[22] T. Halward, T. Stalker, E. LaRue, and G. Kochert, "Use of single-primer DNA amplifications in genetic studies of peanut (Arachis hypogaea L.)," Plant Molecular Biology, vol. 18, no. 2, pp. 315-325, 1992.

[23] SAS Institute, SAS/STAT User's Guide, Version 6, SAS Institute, Cary, NC, USA, 4th edition, 1989.

[24] M. J. Kearsey and A. G. L. Farquhar, "QTL analysis in plants; where are we now?” Heredity, vol. 80, no. 2, pp. 137-142, 1998.

[25] M. J. Kearsey and V. Hyne, "QTL analysis: a simple 'markerregression' approach," Theoretical and Applied Genetics, vol. 89, no. 6, pp. 698-702, 1994.

[26] C. S. Haley and S. A. Knott, "A simple regression method for mapping quantitative trait loci in line crosses using flanking markers," Heredity, vol. 69, no. 4, pp. 315-324, 1992.

[27] B. M. Atta, T. Mahmood, and R. M. Trethowan, "Relationship between root morphology and grain yield of wheat in NorthWestern NSW, Australia," Australian Journal of Crop Science, vol. 7, no. 13, pp. 2108-2115, 2013.

[28] N. T. Lang, C. T. Nha, P. T. T. Ha, and B. C. Buu, "Quantitative trait loci (QTLs) associated with drought tolerance in rice (Oryza sativa L.)," Sabrao Journal of Breeding and Genetics, vol. 45, no. 3, pp. 409-421, 2013.

[29] H. J. Schenk and R. B. Jackson, "Mapping the global distribution of deep roots in relation to climate and soil characteristics," Geoderma, vol. 126, no. 1-2, pp. 129-140, 2005.

[30] A. Srividya, L. R. Vemireddy, P. V. Ramanarao et al., "Molecular mapping of QTLs for drought related traits at seedling stage under PEG induced stress conditions in rice," American Journal of Plant Sciences, vol. 2, no. 2, pp. 190-201, 2011.

[31] N.-N. Shukor, H. A. Hamid, A. Abdu, and M.-K. Ismail, "Effects of soil compaction on growth and physiological characteristics of Azadirachta excelsa seedlings," The American Journal of Plant Physiology, vol. 10, no. 1, pp. 25-42, 2015.

[32] P. R. Bhat, Phenotyping and molecular analysis of Coffea arabica L. accessions and mapping population to identify RAPD markers associated with root characteristics and associated physiological traits [Ph.D. thesis], University of Agricultural Sciences, Bangalore, India, 2002.

[33] S. Chandra, H. K. Buhariwalla, J. Kashiwagi et al., "Identifying QTL linked markers in marker-29 deficient crops," in Proceedings of the 4th International Crop Science Congress, Brisbane, Australia, 2004.

[34] H. M. Pearl, C. Nagai, P. H. Moore, D. L. Steiger, R. V. Osgood, and R. Ming, "Construction of a genetic map for arabica coffee," Theoretical and Applied Genetics, vol. 108, no. 5, pp. 829-835, 2004.

[35] P. Lashermes, M. C. Combes, N. S. Prakash, P. Trouslot, M. Lorieux, and A. Charrier, "Genetic linkage map of Coffea canephora: effect of segregation distortion and analysis of recombination rate in male and female meioses," Genome, vol. 44, no. 4, pp. 589-596, 2001.

[36] P. Hendre, S. Lalji Singh, and R. K. Aggarwal, "Construction of framework molecular linkage map of Robusta coffee, Coffea canephora with RAPD, AFLP, g-SSRs And EST-SSRs using pseudo-testcross strategy," in Proceedings of the Plant \& Animal Genomes 15th Conference, January 2007. 

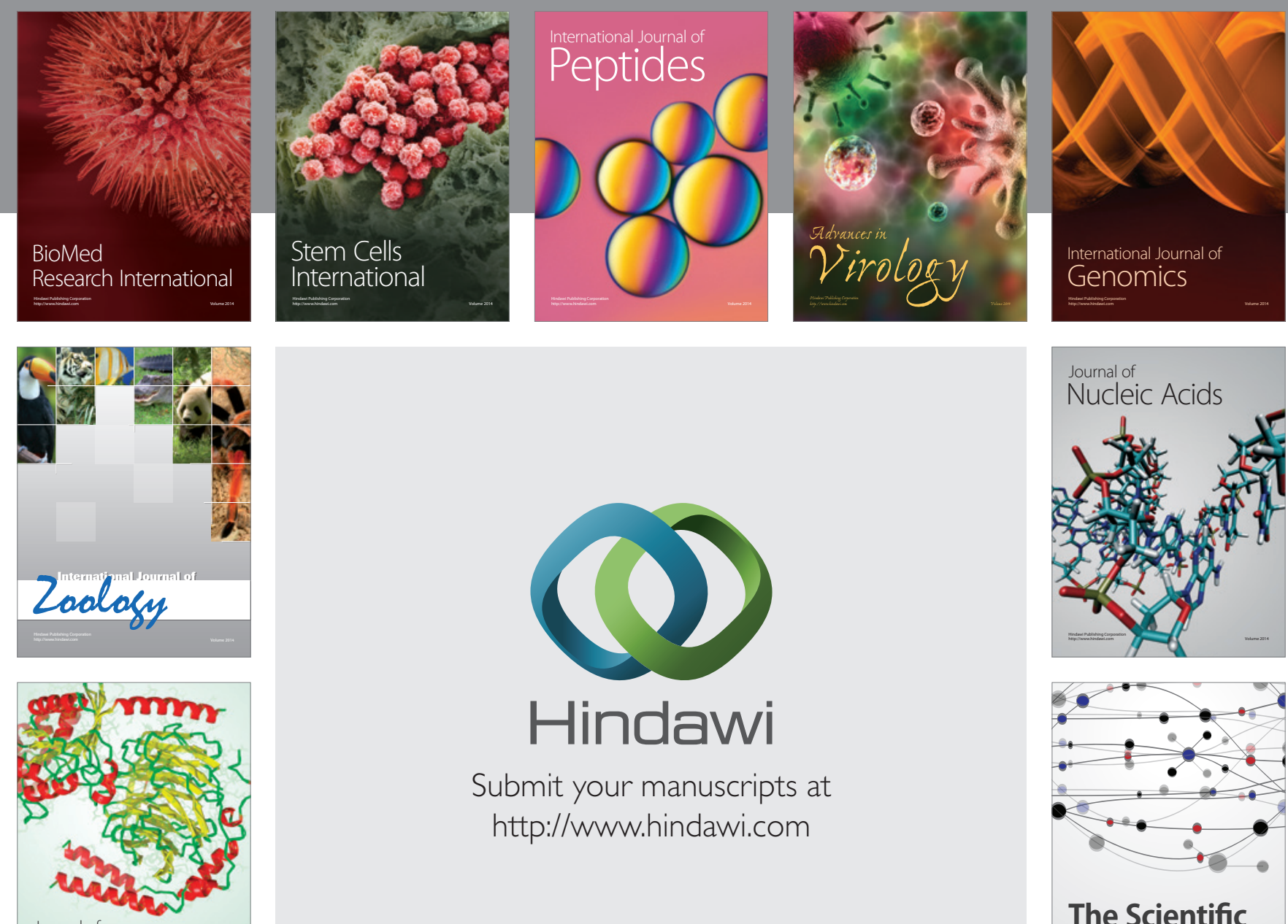

Submit your manuscripts at

http://www.hindawi.com

Journal of
Signal Transduction
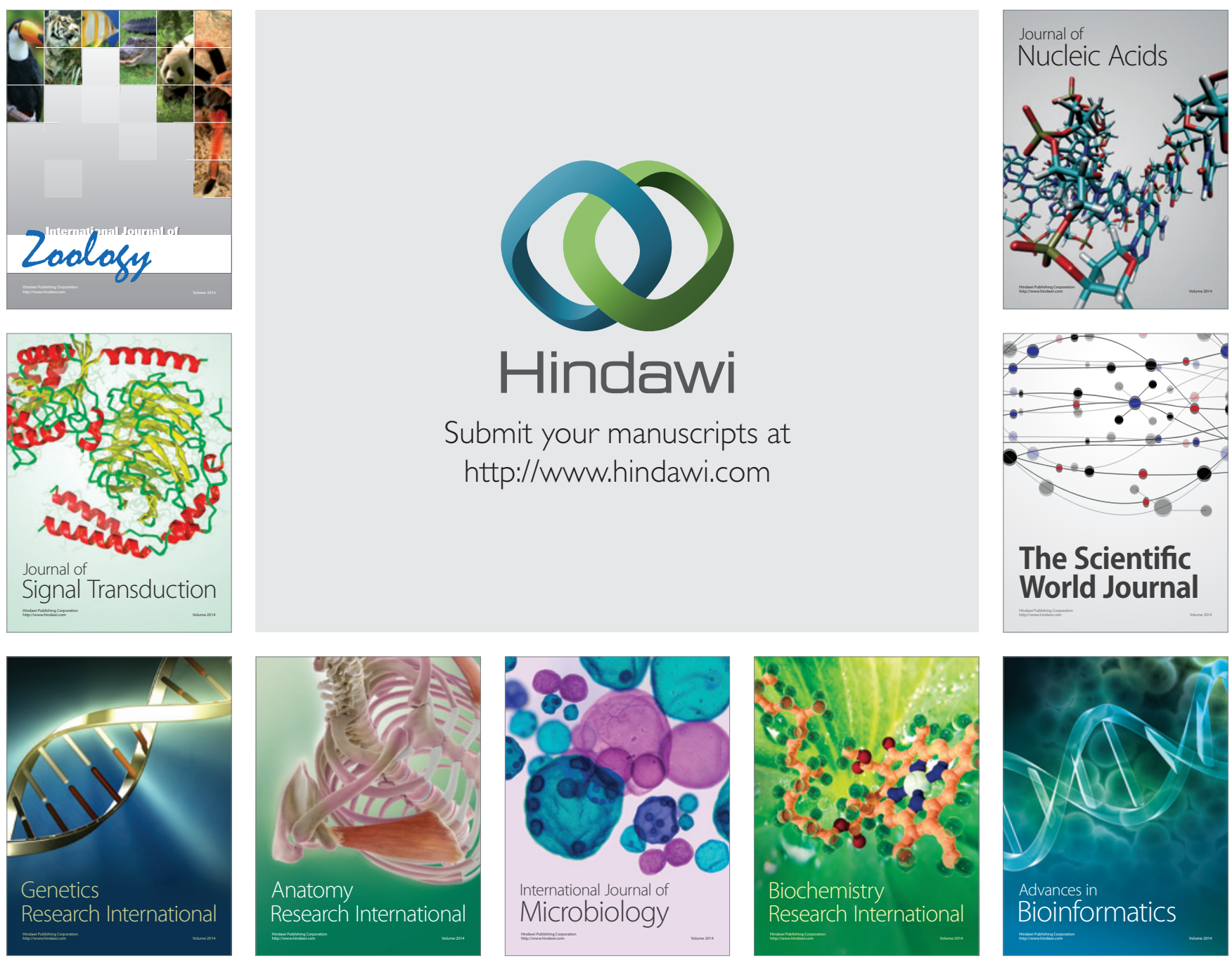

The Scientific World Journal
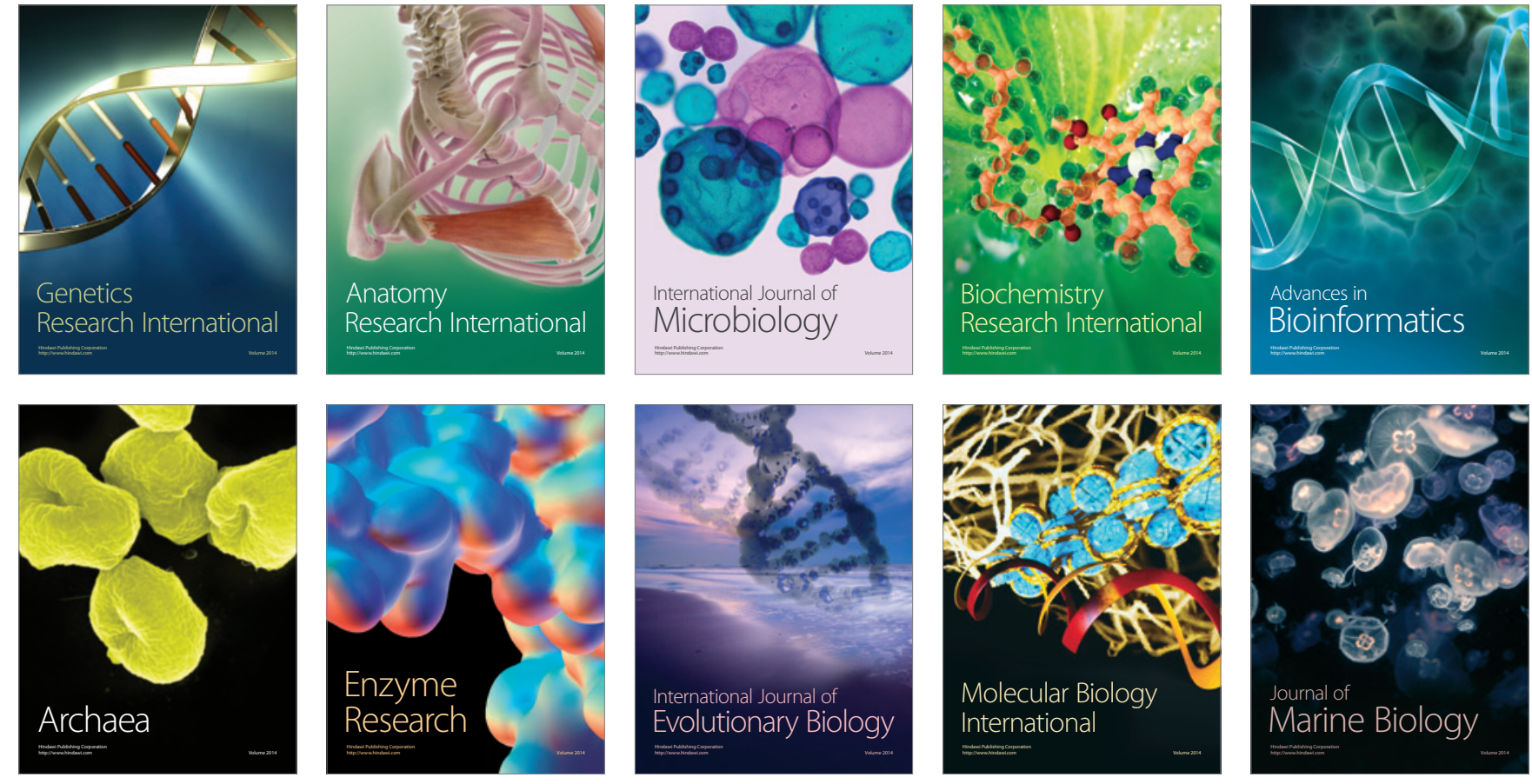